\title{
Resenha do Livro "Sacando" o Voleibol, de Wanderley Marchi Júnior
}

\author{
Juliana Vlastuin* \\ Luiz Alberto Pilatti**
}

\begin{abstract}
RESUMO: O livro de Wanderley Marchi Júnior, "Sacando" o Voleibol, estuda o processo de ressignificação do voleibol brasileiro, em consonância com as disposições e perspectivas da sociedade de consumo, num período circunscrito. A análise histórica da modalidade detecta transições, denominadas pelo autor de viradas. As viradas ocorreram com a passagem do amadorismo para o profissionalismo e com a espetacularização do esporte. A obra apresentada mostra que as estruturas atuais do voleibol não estão perspectivando exclusivamente a criação de um contingente populacional de praticantes, e sim um emergente mercado consumidor de símbolos e signos sociais circunscritos aos capitais de uma prática esportiva distintiva.
\end{abstract}

PALAVRAS-CHAVE: Voleibol: Fatores socioeconômicos. Esportes: História. Resenhas de livros.

"Sacando" o Voleibol, de Wanderley Marchi Júnior, é um daqueles trabalhos que rapidamente encontra eco no meio acadêmico. Inspirada nos escritos do francês Pierre Bourdieu, a obra é uma refinada leitura sociológica de uma modalidade que, em um curto espaço de tempo, foi alçada à condição de segunda modalidade na preferência dos espectadores brasileiros, atrás apenas do futebol. Esse movimento constitui o objeto focado no esquadrinhamento.

O livro é pautado pela idéia de que o esporte moderno não pode ser compreendido suficientemente sem sua consideração como um

* Mestre em Educação Física na linha de pesquisa Sociologia do Esporte, pela Universidade Federal do Paraná. Pesquisadora do Centro de Pesquisa em Esporte, Lazer e Sociedade. Curitiba, PR, Brasil. E-mail: jvlastuin@brturbo.com.br

" Doutor em Educação Física, pela Universidade Estadual de Campinas. Atua no Programa de Pós-Graduação em Engenharia de Produção pela Universidade Tecnológica Federal do Paraná. Curitiba, PR, Brasil. E-mail: lapilatti@utfpr.edu.br 
fenômeno social e historicamente determinado. Com as modificações na vida societária, impostas pelo capitalismo, o esporte, que nasceu na Inglaterra com uma feição aristocrática e elitista, é metamorfoseado. A nova conformação, difundida globalmente, foi permeada por uma lógica mercantil.

Na história dos esportes são visíveis os momentos que traduzem diversos planos de contradições inscritas na prática diária de uma modalidade. Tais circunstâncias, as quais não necessariamente se encontram explícitas nas propostas, mas diluídas, foram identificadas como instrumentos disciplinadores da juventude; na construção do conceito de cidadania disfarçada pelo espírito nacionalista e pelo civismo; nos elementos de disseminação do movimento estudantil, elitizadores e selecionadores de determinado contingente populacional que possuísse as condições de performance física, em detrimento da capacidade intelectual e, por último, no estado atual de mercadoria rentável, profissão e espetáculo.

Assim, o voleibol constituiu-se como um esporte moderno, a partir de uma trajetória baseada na criação de um jogo, que atendesse a sinais peculiares de classes distintas, travestido pelo discurso de elemento da formação integral na Educação Física escolar.

Compreendendo, sumariamente, o conceito de esporte como uma atividade física em constante evolução, estruturada e balizada a partir de uma perspectiva sociocultural, e em contínuo processo de maturação e resignificação é que se inscreve, mediante tais linhas de preocupações, o livro de Marchi Júnior; instigando o leitor a refletir sobre a trajetória do voleibol nacional nas três últimas décadas, diante das perspectivas traçadas pelo amplo espectro de abordagem do fenômeno esportivo. Publicado pela Hucitec e lançado no $9^{\circ} \mathrm{Con}$ gresso de História do Esporte, Lazer e Educação Física, o livro é resultado de seu doutoramento apresentado à Faculdade de Educação Física da Unicamp. Nele, Marchi Júnior fixa um modelo de análise nas indagações iniciais, filtrado em constatações empíricas de que hoje o voleibol e a maioria dos esportes que traçaram o caminho da espetacularização, talvez não estejam sendo trabalhados com a perspectiva de estimular a criação de uma parcela de praticantes desta modalidade, de modo a oportunizar a participação e

Movimento, Porto Alegre, v. 14, n. 03, p. 237-243, setembro/dezembro de 2008. 
aprendizagem, conforme objetivos explicitados em projetos e propostas. Talvez o voleibol tenha evoluído tanto na condição de pertencimento do seu universo prático, quanto no capital específico necessário para o consumo e a inserção do espectador.

Ao utilizar a narrativa de sua própria experiência esportiva, o autor tenta aproximar e ilustrar, minimamente, a transformação ocorrida na modalidade. Para isso, assinala os momentos de rupturas e transições na história da modalidade no Brasil, desde a fase romântica, ou amadora, até a de mercadoria espetacularizada, caracterizando o período de intervalo entre as décadas de 70 e 90.

Tendo em vista a explicitação teórico-metodológica, Marchi Júnior realizou uma pesquisa histórica e descritiva do voleibol, relacionando-a a um processo de análise sociológica, em que os atores e as estruturas sociais aparecem subentendidos ou não de acordo com a descrição.

Dividido em três capítulos, o trabalho discute, no primeiro capítulo, denominado Para análise do Campo Esportivo, a retomada das possíveis configurações da sociologia dos esportes modernos. Para tanto, o autor passa pela exposição das principais leituras teóricas, destacando alguns autores que contornaram traços identificadores do fenômeno, inscrevendo possíveis teorizações ou incursões das mesmas na narrativa.

Assim, para Eric Hobsbawm, analisa o autor, é fundamental associar a história dos esportes ao desenvolvimento da sociedade burguesa na Inglaterra, principalmente por levar em conta a hegemonia da referida nação em diversos setores. Allen Guttmann postula a necessidade de entendimento do esporte pelas matrizes antropológicas e culturais do jogo, associando o perfil dos esportes aos aríetes da modernidade e ressalta que uma nova forma de organização é dada, diferente das estipuladas na Antigüidade e na Idade Média. Bourdieu preconiza que as manifestações que compõem o fenômeno esportivo ocupam um espaço de práticas sociais chamado de campo, no qual atribuem-se posições compatíveis com o capital social, econômico e cultural de cada componente. Preliminarmente, dentro dos parâmetros de análise de Norbert Elias, o surgimento do esporte moderno ocorreu

Movimento, Porto Alegre, v. 14, n. 03, p. 237-243, setembro/dezembro de 2008. 
por conta de sua associação ao processo de civilização ocidental desencadeador de uma série de transformações nos costumes e hábitos da sociedade, originalmente sendo atribuições das classes sociais elevadas; porém, a partir da metade do século XIX, as modalidades entrariam numa fase de absorção da sua prática pelas classes médias e operariado. Na seqüência, Marchi Júnior aprofunda-se na opção teórico-metodológica de análise, justificando sua pertinência e os motivos relacionados à sua escolha. Ainda nesse capítulo, detalham-se os principais conceitos do modelo de análise sociológica de Bourdieu, além da teoria do jogo competitivo e algumas categorias fundamentais da teoria elisiana.

No segundo capítulo, Delimitando o Campo Esportivo: o Voleibol, é mostrado o contexto histórico inicial do voleibol, identificando a invenção da modalidade, ou seja, a caracterização de suas condições históricas, bem como suas vias de expansão e divulgação internacional. $\mathrm{O}$ autor ressalta o surgimento dos órgãos de sustentação institucional e legal que amparam a modalidade no que diz respeito ao seu gerenciamento. Do conjunto das observações apresentadas, tem-se que a história do voleibol respeitou um trajeto que se desviou da exclusividade eurocêntrica na criação de jogos desportivizados e práticas culturais. Nesse sentido, o trabalho aprofunda a discussão e análisa se na origem diferenciada do voleibol não estaria embutido um sistema de disposições que potencializam um novo campo social esportivo. E mais, qual seria a lógica das relações sociais determinadas no desenvolvimento da modalidade. Na segunda parte desse capítulo, evidencia-se o momento de projeção internacional do Voleibol e sua inserção no Brasil, destacando locais e personagens, sendo nesse período caracterizado como o tratamento amador da modalidade, identificado como a fase romântica do Voleibol brasileiro.

No terceiro capítulo, Do All Látex ao Asics Tiger: o processo de ressignificação do Voleibol, é descrita a tentativa de superação da versão amadora do voleibol e a busca da profissionalização e modernização do esporte no Brasil. Nessa esteira, são destacadas as principais inter-relações estabelecidas no campo esportivo, assim como a incursão das empresas e da mídia na modalidade. O conjunto dessas explicita a "primeira virada" no Voleibol brasileiro. Assim, o

Movimento, Porto Alegre, v. 14, n. 03, p. 237-243, setembro/dezembro de 2008. 
percurso da profissionalização e das relações com a mídia reservou um acentuado progresso para a modalidade ao oferecer condições de desenvolvimento técnico e aceitação popular. Essas condições seriam decorrentes dos investimentos das empresas e do marketing esportivo, porém, administradores, técnicos e atletas não se mostraram adequadamente preparados para essa virada e, assim, Marchi Júnior nos transporta diante do cenário de estruturação do voleibol na década de 80 , através do surgimento dos primeiros indícios da nova estrutura como o desenvolvimento do modelo brasileiro de gestão do voleibol; o surgimento das primeiras Associações Desportivas Classistas; o processo de patrocínio das empresas às equipes de voleibol, enfim, à representação progressista do voleibol que, em princípio, aconteceu pela inter-relação firmada entre empresa, mercado e esporte. Nessa óptica, seguem no tópico seqüente, As Dimensões da Espetacularização do Voleibol na Década de 1990, a discussão central sobre como, no decorrer dessa fase, foi delineada a "segunda virada" no voleibol e as conseqüências advindas dessa transição até o final de 2000 .

Na última parte de seu trabalho, Marchi Júnior esclarece as conclusões de seu estudo, apresentando a posição distintiva do voleibol e prováveis possibilidades baseadas em tendências para futuras relações, interdependências e reflexos no campo esportivo que, segundo o autor, desencadeará a provável "terceira virada", na qual o voleibol brasileiro estará inserido.

Se a sociologia como conhecimento não pode dispensar a imaginação, igualmente não pode abrir mão da análise. Desse equilíbrio bem dosado de especulações ou de suposições baseadas em tendências, Marchi Júnior privilegia um momento-chave do atual esporte brasileiro, do qual procura estabelecer um modelo de gerenciamento esportivo que busque a incorporação de conceitos modernos da economia de mercado, a fim de elevar o indicativo de uma nova tendência participativa e/ou interativa do esporte. Tendo em vista essa explicitação, o autor, através de uma pesquisa histórica e descritiva em aproximadamente três décadas recentes, reporta-nos a uma leitura do voleibol, no que diz respeito ao seu processo transitório, caracterizado pela passagem do período de amadorismo para o de

Movimento, Porto Alegre, v. 14, n. 03, p. 237-243, setembro/dezembro de 2008. 
profissionalismo e, posteriormente, de espetacularização do esporte. A partir de algumas estratégias bem exploradas, o autor torna os eventos narrados do passado presentes ao leitor.

Assim, através da sociologia, com uma visão centrada nas práticas corporais, Marchi Júnior produz uma leitura original dos processos perquiridos. Esse é o desenho de uma obra que merece ser lida.

Movimento, Porto Alegre, v. 14, n. 03, p. 237-243, setembro/dezembro de 2008. 
Summary of The Book "Catching" the Volleyball by Wanderley Marchi Júnior

Abstract: The book of the Wanderley Marchi Júnior, "Catching" the Volleyball, it studies the process of remaining of the Brazilian Volleyball, along with the prospects and dispositions of a consume society, in circunscript period. The historical analysis of modality detects the transitions, named by the author as "upturns". The "upturns" occurred with the passage of the amateur to the professional and with the spectacle of the sport. The work presented is that the present structures of Volleyball aren't coping with the creation of a contingent of population players exclusively, but an emerging consuming market of social symbols and signs attached to the capital of a distinct sport practice.

Keywords: Volleyball: Socioeconomic factors. Sports: History. Book reviews.

Reseña del Libro "Entendiendo" el Voley de Wanderley Marchi Júnior

Resumen: El libro de Wanderley Marchi Júnior, "Entendiendo" el Voleibol, del amateurismo a la espectacularización de la modalidad en Brasil (1970-2000), estudia el proceso de resignificación del Voleibol brasilero, en consonancia con las disposiciones y perpectivas de la sociedad de consumo, en un período circunscripto. El análisis histórico de la modalidad detecta transiciones, denominadas por el autor de "cambios". Los "cambios" ocurrieron con el pasaje del amateurismo para el profesionalismo y con la espectacularización del deporte. El trabajo presentado es de que las estructuras actuales del Voleibol no están perpectivando exclusivamente la creación de un gran contingente de practicantes, y si un emergente mercado consumidor de símbolos e signos sociales circunscriptos a los capitales de una práctica deportiva distinta.

Palabras clave: Voleibol: Factores socioeconómicos. Deportes: Historia. Reseña de libros.

\section{REFERÊNCIA}

MARCHI JR., Wanderley. “Sacando” o Voleibol. São Paulo: Hucitec; ljuí: Unijuí, 2004.

Recebido em: 28/05/07

Aprovado em: 22/03/08

Movimento, Porto Alegre, v. 14, n. 03, p. 237-243, setembro/dezembro de 2008. 